University of Nebraska - Lincoln

DigitalCommons@University of Nebraska - Lincoln

Comparison of Three Alternative ANN Designs for Monthly Rainfall-Runoff Simulation

Jurgen D. Garbrecht

USDA

Follow this and additional works at: https://digitalcommons.unl.edu/usdaarsfacpub

Part of the Agricultural Science Commons

Garbrecht, Jurgen D., "Comparison of Three Alternative ANN Designs for Monthly Rainfall-Runoff Simulation" (2006). Publications from USDA-ARS / UNL Faculty. 463.

https://digitalcommons.unl.edu/usdaarsfacpub/463

This Article is brought to you for free and open access by the U.S. Department of Agriculture: Agricultural Research Service, Lincoln, Nebraska at DigitalCommons@University of Nebraska - Lincoln. It has been accepted for inclusion in Publications from USDA-ARS / UNL Faculty by an authorized administrator of DigitalCommons@University of Nebraska - Lincoln. 


\title{
Comparison of Three Alternative ANN Designs for Monthly Rainfall-Runoff Simulation
}

\author{
Jurgen D. Garbrecht ${ }^{1}$
}

\begin{abstract}
The performance of three artificial neural network (ANN) designs that account differently for the effects of seasonal rainfall and runoff variations were investigated for monthly rainfall-runoff simulation on an $815 \mathrm{~km}^{2}$ watershed in central Oklahoma. The ANN design that accounted explicitly for seasonal variations of rainfall and runoff performed best by all performance measures. Explicit representation of seasonal variations was achieved by use of a separate ANN for each calendar month. For the three ANN designs tested, a regression of simulated versus measured runoff displayed a slope slightly under 1 and positive intercept, pointing to a tendency of the ANN to underpredict high and overpredict low runoff values.
\end{abstract}

DOI: 10.1061/(ASCE)1084-0699(2006)11:5(502)

CE Database subject headings: Neural networks; Flow simulation; Seasonal variations; Streamflow; Rainfall.

\section{Introduction}

In recent years, artificial neural network (ANN) applications in hydrology have gained renewed consideration (e.g., Kişi 2004; Coulibaly et al. 2001; ASCE 2000a,b; Elshorbagy et al. 2000; Thirumalaiah and Deo 2000; Tokar and Markus 2000). In particular, the problem of rainfall-runoff, with its underlying complexity in physical processes and nonlinear relationships, was found to lend itself to ANN simulation (Hsu et al. 1995; Wu et al. 2005).

Understanding the fundamentals of ANN and the dominant features of the modeled hydrologic system is critical to developing an effective ANN design. Pronounced nonlinearities in runoff generation between high, medium, and low rainfall events suggest that a single ANN may be less effective at simulating the full range of rainfall events than separate ANNs for low, medium, and high rainfall events. Zhang and Govindaraju (2000) built on this interpretation and proposed a modular neural network (MNN) where different modules within the network were trained to learn subsets of the rainfall-runoff input space. In this study, an ANN was designed for improved simulation of the effects of seasonal climate variations on runoff for an $815 \mathrm{~km}^{2}$ watershed in central Oklahoma. In central Oklahoma, rainfall is bimodal, with peaks in May and September. Winter months have predominantly frontal type rainfall (light, prolonged rain), dormant vegetation, low evapotranspiration (ET), moist soils, and runoff that is mostly

\footnotetext{
${ }^{1}$ Research Hydraulic Engineer, U.S. Dept. of Agriculture, Agricultural Research Service, Grazinglands Research Laboratory, 7207 West Cheyenne St., El Reno, OK 73036. E-mail: Jurgen.Garbrecht@ ars.usda.gov

Note. Discussion open until February 1, 2007. Separate discussions must be submitted for individual papers. To extend the closing date by one month, a written request must be filed with the ASCE Managing Editor. The manuscript for this technical note was submitted for review and possible publication on May 10, 2005; approved on September 14, 2005. This technical note is part of the Journal of Hydrologic Engineering, Vol. 11, No. 5, September 1, 2006. CASCE, ISSN 1084-0699/2006/ 5-502-505/\$25.00.
}

slow subsurface return flow. On the other hand, summer months have convective type rainfall (high intensity rain), active vegetation, high ET, dry soils, and runoff that is in large part direct runoff. Thus, an ANN design that can account for such variations in seasonal climate and hydrologic conditions is believed to lead to a better rainfall-runoff transfer function and to better enhance runoff simulations than anN that lumps all seasons together. Here, calendar month identification was used to capture the effects of seasonal rainfall and runoff variations.

Three ANN designs with different representation for calendar month were compared, and the performance of each design was tested based on the ANN's ability to reproduce observed monthly runoff on the $815 \mathrm{~km}^{2}$ Fort Cobb watershed in central Oklahoma. The goals of this ANN study were to: (1) alert users of ANN to the importance of proper ANN design and encourage exploration of alternative designs; (2) illustrate differences in performance of rainfall-runoff simulation between the three proposed ANN designs; and (3) identify an ANN design with high simulation performance for monthly rainfall-runoff applications for central Oklahoma conditions.

\section{ANN Application and Evaluation}

Average monthly rainfall over the watershed was calculated from 1940-2004 daily rainfall observations at four nearby Natural Weather Service (NWS) stations. Monthly watershed runoff was available for 1940 through 1958 from the U.S. Geological Survey and for 1963 through 2004 from the Bureau of Reclamation. Monthly runoff was simulated by the commercial ANN software BrainMaker (Lawrence 1994). BrainMaker is a standard feedforward, back-propagation neural network that relates a set of known input variables to one or several desired output variables.

Input variables for ANN Design 1 consisted of total rainfall for the current month and for each of the previous two months. Rainfall of the current month was considered to be the main causal driver for runoff, and rainfall for the previous two months re- 
Table 1. Monthly ANN Performance Measures Based on Testing Data Set

\begin{tabular}{|c|c|c|c|c|c|c|c|c|c|c|c|c|}
\hline \multirow[b]{2}{*}{ Month } & \multicolumn{4}{|c|}{ Design 1} & \multicolumn{4}{|c|}{ Design 2} & \multicolumn{4}{|c|}{ Design 3} \\
\hline & $R^{2}$ & $S$ & $I$ & $\begin{array}{c}\Delta \\
(\%)\end{array}$ & $R^{2}$ & $S$ & $I$ & $\begin{array}{c}\Delta \\
(\%)\end{array}$ & $R^{2}$ & $S$ & $I$ & $\begin{array}{c}\Delta \\
(\%)\end{array}$ \\
\hline January & 0.12 & 0.03 & 1.93 & -28 & 0.86 & 0.42 & 1.27 & -13 & 0.80 & 0.39 & 1.05 & -24 \\
\hline February & 0.35 & 0.05 & 1.67 & -40 & 0.71 & 0.58 & 0.88 & -13 & 0.57 & 0.35 & 1.64 & -13 \\
\hline March & 0.71 & 0.69 & 1.77 & -1 & 0.71 & 0.78 & 1.51 & 4 & 0.68 & 0.73 & 2.20 & 10 \\
\hline April & 0.86 & 0.88 & -0.15 & -15 & 0.89 & 0.79 & 0.24 & -9 & 0.92 & 0.90 & 0.56 & 0 \\
\hline May & 0.82 & 0.60 & 5.02 & 16 & 0.77 & 0.65 & 4.73 & 18 & 0.91 & 0.80 & 1.46 & -4 \\
\hline June & 0.95 & 0.58 & 2.26 & -30 & 0.95 & 0.92 & 0.51 & -3 & 0.95 & 0.99 & -0.05 & -1 \\
\hline July & 0.37 & 0.82 & 2.35 & 48 & 0.91 & 0.84 & 1.06 & 13 & 0.63 & 0.56 & 1.79 & 6 \\
\hline August & 0.42 & 0.06 & 1.67 & -34 & 0.75 & 0.48 & 1.12 & -11 & 0.61 & 0.43 & 1.27 & -11 \\
\hline September & 0.20 & 0.47 & 2.02 & 35 & 0.85 & 1.08 & 0.41 & 25 & 0.78 & 1.29 & -0.10 & 25 \\
\hline October & 0.97 & 1.54 & -1.61 & 4 & 0.98 & 0.94 & 0.02 & -5 & 0.98 & 0.94 & -0.27 & -15 \\
\hline November & 0.76 & 0.98 & 0.23 & 5 & 0.97 & 1.04 & -0.41 & -9 & 0.71 & 0.67 & 0.90 & -5 \\
\hline December & 0.46 & 0.79 & 0.92 & 12 & 0.55 & 0.63 & 1.29 & 10 & 0.80 & 0.65 & 1.20 & 8 \\
\hline Mean & 0.58 & 0.62 & 1.42 & -2 & 0.83 & 0.77 & 1.05 & 1 & 0.76 & 0.73 & 0.97 & -2 \\
\hline Absolute mean & & & & 22 & & & & 11 & & & & 10 \\
\hline
\end{tabular}

Note: $R^{2}=$ coefficient of determination; $S$ and $I=$ slope and intercept $\left(\mathrm{Mm}^{3}\right)$ of linear regression; and $\Delta=$ difference in simulated runoff in percent of observed runoff.

flected antecedent conditions and hydrologic system memory. Other inputs consisted of expected exceedance rainfall, which was quantified in terms of three threshold values for monthly rainfall. Monthly rainfall below the low threshold was likely to produce very little runoff, with most of the rainfall entering the soil profile and contributing to evapotranspiration; monthly rainfall exceeding the high threshold was likely to produce a large runoff volume. The threshold values were chosen subjectively by examination of the rainfall-runoff scatter plot for the watershed under consideration. The last inputs were 12 binary calendar month identifiers. The total number of input nodes for Design 1 was 18 , and the number of hidden nodes was 10 . The number of hidden nodes was kept lower than the number of input nodes to enhance the learning potential of the network. Monthly runoff volume was the only output variable.

In Design 2, a separate and independent ANN was developed for each calendar month, thereby accounting explicitly for seasonal variations. Input consisted of the same rainfall variables used in Design 1, but without the calendar month identifier and with one or more input variables omitted, based on rainfall-range consideration and trial-and-error network optimization. For example, during the dry winter months, the high exceedance rainfall threshold was never exceeded and was removed from the input data set, thereby also reducing the number of hidden nodes in the network. The number of input nodes for the 12 ANN ranged from 3 to 6 , and the number of hidden nodes ranged from 2 to 4 . The shortcoming of this design was the comparatively smaller training and testing data set for each network. However, the seasonal variations of the climate and runoff response might be better reproduced, potentially leading to a better year-round rainfall-runoff simulation.

In Design 3, the ANN considered rainfall and runoff data from three consecutive months for the training phase, yet for the simulation phase only rainfall-runoff data for the center months were used to drive the ANN. Thus, 12 separate ANNs were again developed, one for each calendar month. This third design overcame the shortcoming of the second design by tripling the training data set from which each ANN can learn, while at the same time still accounting for the seasonal variations of the climate and rainfall- runoff relation. The fundamental assumption was that seasonal effects and rainfall-runoff behavior of neighboring months were similar. Input consisted again of the same rainfall variables and the month identifier for the three months under consideration. The number of input nodes ranged from 7 to 9 , and the number of hidden nodes ranged from 4 to 7.

Rainfall and runoff data were available for 734 months, of which 624 values $(85 \%)$ were used for training and $110(15 \%)$ were used for testing. Testing values were selected subjectively from the 1940-2003 data set to ensure that each month had about the same number of test values and that they covered the full range of rainfall and runoff values within each month. Because large rainfall and runoff values were very infrequent as compared to medium and low values, it was felt that the two largest rainfallrunoff values for each month were absolutely necessary in the training data set. However, this would have limited the testing to mostly medium and small values. Thus, for purely practical reasons and despite introduction of a bias in the testing, the two highest rainfall-runoff values were also used in the testing. While this may impact the measure of ANN performance, it was not believed that the "relative difference" in performance between designs was greatly affected. The testing data set was also augmented by the recently obtained 2004 observed monthly rainfall and runoff data. The identical training and test data were used for all three designs.

\section{Results}

\section{Month-by-Month ANN Performance}

The testing data set of 110 pairs of monthly rainfall-runoff, values were used to simulate monthly runoff, which was then compared against observed runoff (Table 1). The $R^{2}$ of simulated versus observed runoff for ANN Design 1 was lower than for Designs 2 or 3 for most months. This systematic lower performance of Design 1 was also reflected in the average $R^{2}$ over all months (Table 1, bottom row). Designs 2 and 3 explained about 83 and $76 \%$ of the variability in monthly runoff, respectively, whereas Design 1 
Table 2. Year-Round Monthly ANN Performance Measures Based on Testing Data Set

\begin{tabular}{lcccc}
\hline Design & $R^{2}$ & $S$ & $I$ & $\begin{array}{c}\Delta \\
(\%)\end{array}$ \\
\hline Design 1 & 0.72 & 0.67 & 1.30 & -5 \\
Design 2 & 0.87 & 0.84 & 0.80 & 2 \\
Design 3 & 0.89 & 0.89 & 0.47 & -1 \\
\hline
\end{tabular}

Note: $R^{2}=$ coefficient of determination; $S$ and $I=$ slope and intercept $\left(\mathrm{Mm}^{3}\right)$ of linear regression; and $\Delta=$ difference in simulated runoff in percent of observed runoff.

only explained $58 \%$ of the variability. The slope of the linear regression of simulated versus observed runoff was mostly less than 1.0 and the intercept was larger than 0.0 for all three designs; thus, large runoff values were being underpredicted while small runoff values were being overpredicted. This bias was discussed by Minns and Hall (1996) and attributed to the different runoff generation mechanisms for high and low rainfall events (Zhang and Govindaraju 2000). This month-by-month ANN performance analysis clearly identified the performance of Design 1 to be deficient as compared to the other two designs. Designs 2 and 3 were similar, with Design 2 being a little better than Design 3, mostly due to a higher mean $R^{2}(0.83$ versus 0.76$)$. Runoff simulations for Designs 2 and 3 were generally good for months with high rainfall and runoff (April, May, June, October, and November), whereas they were not as good for winter months (December, January, and February), which generally have low rainfall and predominantly baseflow runoff.

\section{Year-Round Monthly ANN Performance}

Rainfall-runoff for all calendar months were considered together to provide an overall, year-round performance assessment. The same performance criteria as in the previous section were used, and the results are shown in Table 2. The scatter plots of simulated versus observed runoff for all three designs are shown in Fig. 1. In this evaluation, the ANN Designs 2 and 3 again outperformed Design 1 in all performance measures, while Designs 2 and 3 were essentially equal.

\section{Monthly Time-Series ANN Performance}

In this time-series assessment, the entire 1963-2004 monthly rainfall data (training and testing data sets) were used (734 monthly rainfall-runoff values). Design 1 was again the weakest with respect to all performance measures, while Designs 2 and 3 were similar (Table 3). Design 2 produced a little better $R^{2}$ and a smaller discrepancy in runoff, while Design 3 produced better slope and intercept values. The flow duration curves of simulated and observed monthly runoff for the three designs are displayed in Fig. 2. Designs 2 and 3 followed the observed data closely. The discrepancy in the $70 \%$ probability range was confined to base flow conditions and appeared large due to the logarithmic scale. A measure more frequently used in runoff analysis is the NashSutcliffe efficiency coefficient (NSE) (Nash and Sutcliffe 1970). An NSE coefficient value below 0.3 is considered poor, while a value above 0.75 is good, and a value between 0.36 and 0.75 is satisfactory (Motovilov et al. 1999). Thus, both Designs 2 and 3 are in the good category, whereas Design 1 falls in the fair category. Overall, Designs 2 and 3 outperformed Design 1, with Design 2 slightly better than Design 3.
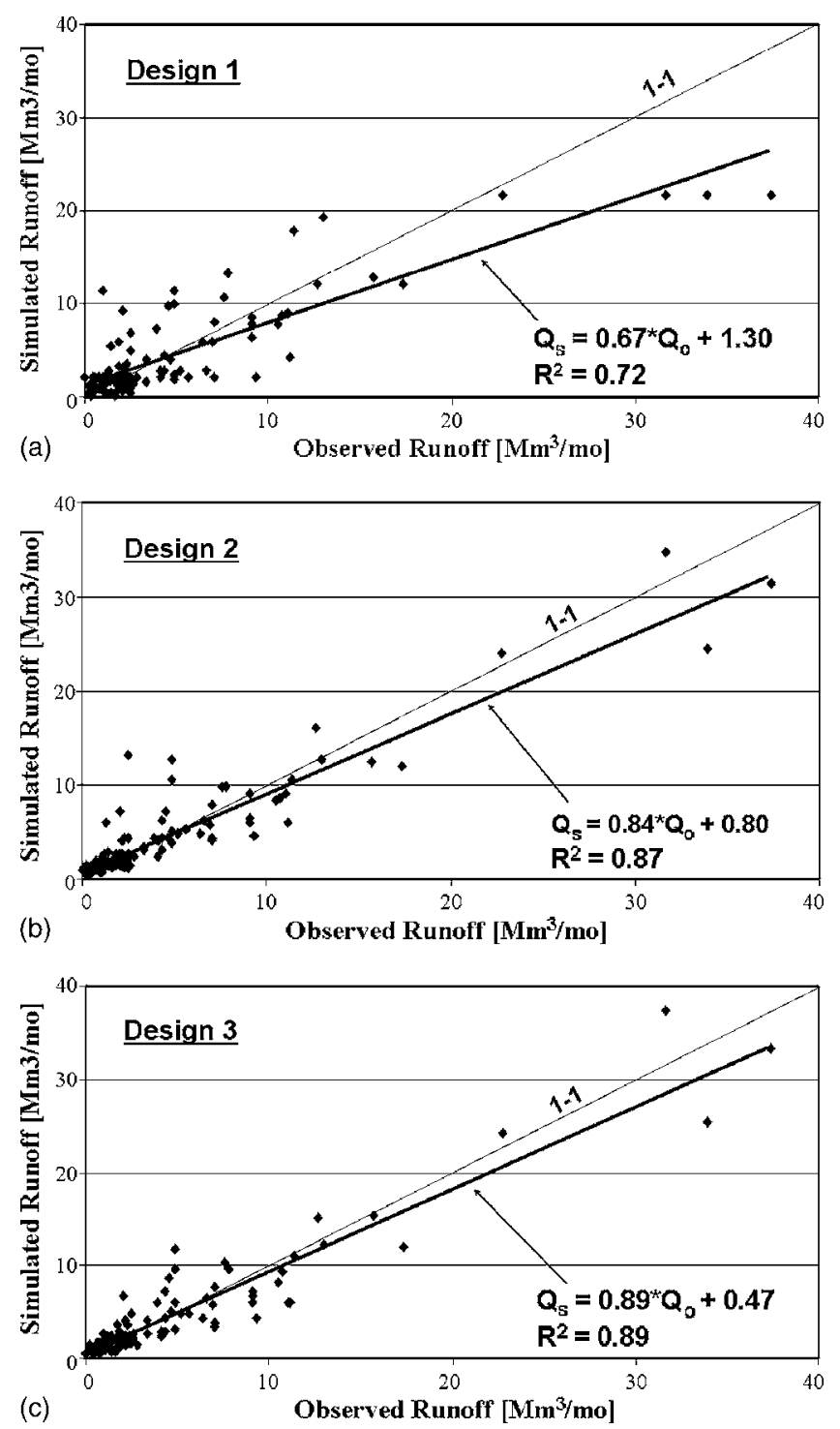

Fig. 1. Scatter plot of simulated versus observed monthly runoff for three ANN designs

\section{Conclusions}

Three different ANN designs for monthly rainfall-runoff simulation were trained and tested with rainfall-runoff data of the $815 \mathrm{~km}^{2}$ Ft. Cobb watershed in central Oklahoma. The main difference between the three designs was the way in which the effects of seasonal climate and runoff variations were incorporated into the ANN. The performance of monthly runoff simulation was

Table 3. ANN Performance Measures for 1963-2004 Time Series

\begin{tabular}{lccccc}
\hline Design & $R^{2}$ & $S$ & $I$ & $(\%)$ & NSE \\
\hline Design 1 & 0.67 & 0.67 & 0.84 & -9 & 0.66 \\
Design 2 & 0.79 & 0.75 & 0.74 & -4 & 0.79 \\
Design 3 & 0.78 & 0.76 & 0.63 & -6 & 0.78 \\
\hline
\end{tabular}

Note: $R^{2}=$ coefficient of determination; $S$ and $I=$ slope and intercept $\left(\mathrm{Mm}^{3}\right)$ of linear regression; $\Delta=$ difference in simulated runoff in percent of observed runoff; and NSE=Nash-Sutcliffe efficiency coefficient. 


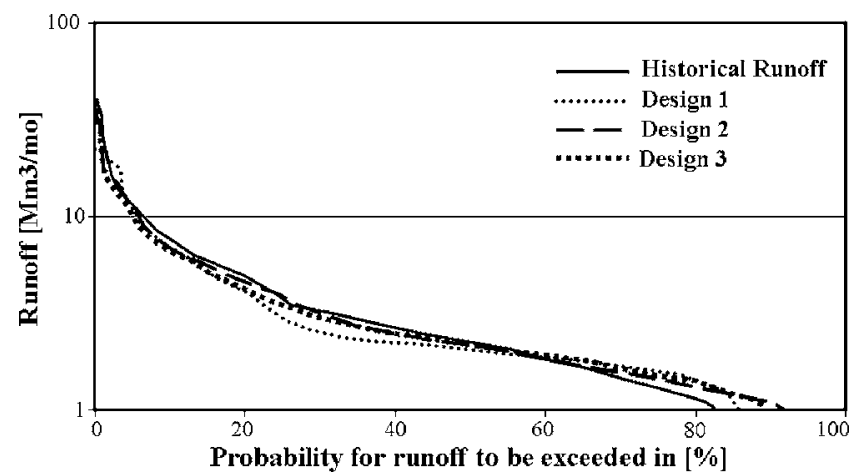

Fig. 2. Runoff duration curves for observed and simulated runoff for: (a) Design 1; (b) Design 2; (c) Design 3

tested for each of the three designs based on the network's ability to reproduce the observed monthly runoff. The following conclusions can be drawn from this investigation:

- ANN design had a significant impact on rainfall-runoff simulation performance and deserves careful consideration when setting up an ANN;

- A separate ANN for each month of the year that explicitly reflected the seasonal rainfall and runoff variations led to better simulation results than corresponding results of a single ANN for all calendar months that implicitly accounted for the seasonal variations;

- A monthly ANN trained with either one month or three consecutive months of observed data produced similar rainfallrunoff simulation results, with the ANN based on one month data being somewhat simpler and displaying overall slightly better performance.

- Base flow during low rainfall months was not well simulated by any ANN design because of the weak relationship between rainfall and base flow during dry months; and

- All three ANN designs systematically underpredicted high and overpredicted low runoff values. A simple, post-ANN linear correction of the simulated runoff could be applied to further enhance runoff simulation performance.

\section{References}

ASCE. (2000a). "Artificial neural networks in hydrology. I: Preliminary concepts." J. Hydrologic Eng., 5(2), 115-123.

ASCE. (2000b). "Artificial neural networks in hydrology. II: Hydrologic applications." J. Hydrologic Eng., 5(2), 124-137.

Coulibaly, P., Anctil, F., and Bobee, B. (2001). "Multivariate reservoir inflow forecasting using temporal neural networks." J. Hydrologic Eng., 6(5), 367-376.

Elshorbagy, A., Simonovic, S. P., and Panu, U. S. (2000). "Performance evaluation of artificial neural networks for runoff prediction." J. Hydrologic Eng., 5(3), 424-427.

Hsu, K., Gupta, H. V., and Sorooshians, S. (1995). "Artificial neural network modeling of the rainfall-runoff process." Water Resour. Res., 31(10), 2517-2530.

Kişi, Ö. (2004). "River flow modeling using artificial neural networks." $J$. Hydrologic Eng., 9(1), 60-63.

Lawrence, J. (1994). Introduction to neural networks, design, theory, and applications, California Scientific, Nevada City, Calif.

Minns, A. W., and Hall, M. J. (1996). "Artificial neural networks as rainfall-runoff models." Hydrolo. Sci., 41(3), 399-417.

Motovilov, Y. G., Gottschalk, L., England, K., and Rodhe, A. (1999). "Validation of a distributed hydrologic model against spatial observations." J. Agric. Forest Meteorol., 98-99, 257-277.

Nash, J. E., and Sutcliffe, J. V. (1970). "River flow forecasting through conceptual models. I: A discussion of principles." J. Hydrol., 10(3), $238-250$.

Thirumalaiah, K., and Deo, M. C. (2000). "Hydrological forecasting using neural networks." J. Hydrologic Eng., 5(2), 180-189.

Tokar, A. S., and Markus, M. (2000). "Precipitation-runoff modeling using artificial neural networks and conceptual models." J. Hydrologic Eng., 5(2), 156-161.

Wu, J. S., Han, J., Annambhotla, S., and Bryant, S. (2005). "Artificial neural networks for forecasting watershed runoff and stream flows." $J$. Hydrologic Eng., 10(3), 216-222.

Zhang, B., and Govindaraju, R. S. (2000). "Prediction of watershed runoff using Bayesian concepts and modular neural networks." Water Resour. Res., 36(3), 753-762. 